\title{
Thromboembolism in Pregnancy: Gynecologists Perspective
}

\author{
Anupama Hari ${ }^{1}$ \\ ${ }^{1}$ Department of Obstetrics \& Gynecology, Malla Reddy Medical \\ College for Women, Hyderabad, Telangana, India
}

Indian J Cardiovasc Dis Women-WINCARS 2018;3:86-97

\begin{abstract}
Address for correspondence Anupama Hari, MD, DGO, DNB, PhD, Department of Obstetrics \& Gynecology, Malla Reddy Medical College for Women, 8-3-224, C-1, Vora Towers, Madhuranagar, Yousufguda Road, Hyderabad, TS 500038, India (e-mail: dranupamahari@gmail.com).
\end{abstract}

\begin{abstract}
Pregnancy is a thrombogenic condition in both antenatal and postpartum periods. Venous thromboembolism (VTE) is a common cause of morbidity, and the cause of maternal death in such situations is pulmonary embolism. There are several risk factors for thrombotic phenomena in pregnancy both acquired and hereditary. Accurate diagnosis of deep vein thrombosis (DVT) and its treatment are very important to prevent life-threatening pulmonary embolism. Among the diagnostic techniques, compression ultrasound is the mainstay for DVT diagnosis, whereas computed tomographic pulmonary angiography (CTPA) is for pulmonary embolism. Anticoagulants play a major role in therapy. They are used both in the active stage of thromboembolism and also in thromboprophylaxis in the postpartum period. Different types of heparins are available, which can be tailored to the individual requirements. During therapy they need monitoring to prevent hemorrhagic complications. Oral anticoagulants cannot be given in pregnancy as a general rule because of their teratogenicity, though they can be used in the postpartum period. Thrombolysis is can be taken up in selected cases in the acute situations. A very prolonged treatment of anticoagulants and compression

Keywords

- venous

thromboembolism

- pulmonary embolism

- anticoagulants in pregnancy stockings are needed in patients with past history of VTE. The most convenient drug regimen for prophylaxis is once-daily weight-adjusted low-molecular-weight heparin (LMWH). The goal of this article is to facilitate the recognition of thromboembolic disorders in pregnancy and different regimens in their management during antenatal, intrapartum, and postpartum periods. A few interesting and rare cases from the author's experience are also presented at the end.
\end{abstract}

\section{Introduction}

Hemostatic system of a woman of reproductive age faces many challenges during her pregnancy, childbirth, and puerperium. During development of embryo to growing fetus, certain processes such as implantation, placentation, and remodeling of the uterine spiral arteries where there is a need for high volume, high flow, and low resistance of uteroplacental circulation occur. For these changes, they require accelerated hemostatic responsiveness to avoid severe ante- and postpartum hemorrhage (PPH).

This essential hemostatic adaptation to human hemochorial placentation may result in increased risk of superficial and deep vein thrombosis (DVT) and pulmonary embolism (PE). ${ }^{1}$ The immediate identification and prompt treatment of thrombotic events is critical to avoid maternal death and serious postthrombotic sequelae.

\section{Incidence}

Venous thromboembolism (VTE) that includes DVT and PE occurs in 0.06 to $0.17 \%$ of pregnancies. ${ }^{2}$ This incidence represents nearly 10 -fold increase compared with nonpregnant women of comparable age group. The risk increases with gestational age with $22 \%$ of thrombotic episodes occurring during first trimester, followed by $34 \%$ during second and $44 \%$ during third trimester. VTE leads to $9 \%$ of maternal deaths 
according to 2010 U.S. statistics. ${ }^{3}$ It is three- to eightfold higher in puerperium because of decreased ambulation. ${ }^{4}$ Latest evidence showed that the risk of VTE extends up to 12 weeks of postpartum period, although the absolute increase in risk is quite low after 6 weeks of postpartum. ${ }^{5}$ The most important risk factor for VTE in pregnancy is a history of previous thrombosis. Approximately 15 to $25 \%$ of thromboembolism (TE) events in pregnancy are recurrent events.

\section{Pathophysiology of Venous Thromboembolism in Pregnancy}

Pregnancy is a thrombogenic hypercoagulable state wherein the three components of Virchow's triad are active simultaneously: stasis of blood, damage to vascular endothelium, and changes in coagulants of blood. First, venous stasis is caused by pressure of distended uterus with growing fetus on inferior vena cava (IVC) and iliac veins. This compression-caused stasis is more prominent in the left leg due to different relative anatomic position of left common iliac vein that is compressed by the right common iliac artery. ${ }^{6}$ Second component that is vessel wall damage occurs during deliveryboth normal and cesarean sections. The third component is an alteration in coagulation factors. Pregnancy is a prothrombotic state, and it is a part of the adaptation mechanism that ensures control of bleeding from placental bed during third stage of labor. ${ }^{7}$ There is increase in levels of procoagulant factors such as V, VII, VIII, IX, X, XII, and fibrinogen along with presence of placental inhibitors of fibrinolysis. Both fibrinolysis and anticoagulant systems are downregulated leading to increase in risk of VTE in pregnancy. Added to these, thrombophilia in pregnancy further increases the risk of TE. After the delivery, the risk of embolism is increased due to release of tissue thromboplastin into circulation at the time of placental separation.

\section{Risk Factors for Venous Thromboembolism during Pregnancy and Puerperium ${ }^{8}$}

Predisposing factors for VTE in pregnancy are many. The risk factors can be classified into two groups:

1. Pregestational risk factors

2. Gestational factors (-Table $\mathbf{1}$ ).

Table 1 Risk factors for VTE

\begin{tabular}{|l|l|}
\hline Pregestational risk factors & Gestational risk factors \\
\hline Age $>35 \mathrm{y}$ & Multiple pregnancy \\
\hline Obesity & $\begin{array}{l}\text { Immobility during antena- } \\
\text { tal/postpartum period }\end{array}$ \\
\hline Smoking & Pregnancy following IVF \\
\hline Sickle cell disease & Cesarean section \\
\hline Diabetes & Postpartum hemorrhage \\
\hline Hypertension & Puerperal infection \\
\hline $\begin{array}{l}\text { Personal or family history } \\
\text { of VTE }\end{array}$ & \\
\hline Thrombophilia & \\
\hline
\end{tabular}

Abbreviation: IVF, in vitro fertilization; VTE, venous thromboembolism.
Heritable Thrombophilia and Venous

Thromboembolism in Pregnancy

Thrombophilia is a disorder of hemostasis that predisposes to a thrombotic event. Recent data suggest that up to $50 \%$ of VTE in pregnancy are associated with an inherited or acquired thrombophilia. ${ }^{9}$ The absolute risk of VTE in pregnancy with thrombophilia is 1 to $2 \%$, and most events occur in postpartum period. ${ }^{10}$ Thrombophilia testing is of limited value in women who have acute VTE in pregnancy, as the result would not alter the clinical management and also because both pregnancy and thrombosis affect the level of circulating clotting factors confounding the test interpretation. ${ }^{11}$ When compared with vaginal delivery, operative cesarean delivery is associated with a substantial ninefold increase in risk of VTE. Admission to the hospital in pregnancy may be associated with 17-fold increased risk for VTE when compared with nonhospitalized pregnant women as inpatients will have restricted mobility. ${ }^{12}$ In vitro fertilization has been shown to increase the risk of VTE in first trimester; it might be due to the increased bedrest taken by the woman because of precious pregnancy. Life time risk of thrombosis is most commonly seen in antithrombin (AT) III deficiency at nearly 70 to $90 \%{ }^{13}$ ( - Table 2).

\section{Diagnosis of Venous Thromboembolism in Pregnancy}

Clinical features of typical DVT include erythema, warmth, pain, edema, and tenderness confined to the area of thrombosis. Occasionally a palpable cord-like thickening may correspond to a thrombosed vein. "Homan's sign" is the pain and tenderness elicited on compression of the calf muscles by squeezing the muscles or by dorsiflexion of the foot. When pain occurs distal to blood pressure (BP) cuff inflated to 180 $\mathrm{mm} \mathrm{Hg}$, it is known as positive Löwenberg test. With all aforementioned signs and symptoms, the diagnosis of DVT is confirmed in only one-third of the patients.

\section{Differential Diagnosis of Deep Vein Thrombosis}

Differential diagnosis of DVT includes cellulitis, ruptured or strained muscle or tendon, trauma, popliteal (Baker's)

Table 2 Inherited thrombophilias in pregnancy ${ }^{13}$

\begin{tabular}{|c|c|c|}
\hline Thrombophilia & $\begin{array}{l}\text { Prevalence } \\
\text { (in healthy } \\
\text { patients) }\end{array}$ & Risk of thrombosis \\
\hline $\begin{array}{l}\text { Antithrom- } \\
\text { bin (AT) III } \\
\text { deficiency }\end{array}$ & $0.02-0.10$ & $\begin{array}{l}\text { Most common congenital } \\
\text { clotting disorder in women } \\
70-90 \% \text { lifetime risk of } \\
\text { thrombosis } \\
60 \% \text { chance of thrombosis } \\
\text { in pregnancy and } 30 \% \text { in } \\
\text { puerperium }\end{array}$ \\
\hline $\begin{array}{l}\text { Factor V Leiden } \\
\text { Def } \\
\text { Heterogenous } \\
\text { Homozygous } \\
\text { Protein C } \\
\text { deficiency } \\
\text { Protein S } \\
\text { deficiency }\end{array}$ & $\begin{array}{l}3.6-6.0 \\
0.1-0.2 \\
0.2-0.5 \\
0.03-1.3\end{array}$ & $\begin{array}{l}10-15 \% \text { during pregnancy } \\
\text { and } 20 \% \text { in puerperium } \\
\text { Risk increases }>100 \% \text { if } \\
\text { homozygous } \\
5 \% \text { during pregnancy and } \\
20 \% \text { during puerperium } \\
5 \% \text { during pregnancy and } \\
20 \% \text { during puerperium } \\
\text { Protein S declines during } \\
\text { normal pregnancy }\end{array}$ \\
\hline
\end{tabular}


cysts, cutaneous vasculitis, superficial thrombophlebitis, and lymphedema.

\section{Diagnostic Algorithm ${ }^{14}$}

Among all investigations, venous ultrasound (VUS) is the most important tool in the diagnosis of DVT (-Fig. 1).

\section{Imaging in Deep Vein Thrombosis}

Contrast venography is associated with risk of radiation and contrast allergy as well as its technical difficulty, so it is not done routinely. VUS with or without color Doppler is the most common diagnostic aid in evaluation of patients with DVT.

Compression VUS involves the application of pressure with the probe to determine whether the affected vein is compressible. The most accurate ultrasonic criterion for diagnosis of venous thrombosis is "noncompressibility" of venous lumen in a transverse plane, under gentle probe pressure using color Doppler. ${ }^{15}$

In a meta-analysis done by Goodacre et al, VUS sensitivity of $96.4 \%$ for proximal (knee, thigh) DVT and $75.2 \%$ for distal (calf) DVT was shown. ${ }^{16}$ The McMaster Diagnostic Imaging Practice Guidelines Initiative suggests that either USG or impedence venography is a first-line test in diagnosis of DVT in pregnant women. When these test results are equivocal, magnetic resonance imaging (MRI) has got a role in diagnosis of DVT. ${ }^{17}$

In case of magnetic resonance angiography (MRA), Meaney et al suggested a sensitivity of $100 \%$, specificity of 95\% in the diagnosis of VTE. ${ }^{18}$ MRA does not cause ionizing radiation; it is an alternative to computed tomography pulmonary angiography (CTPA) in pregnancy. Gadolinium comes under group $\mathrm{C}$ agent and crosses the placenta and is secreted by fetal kidneys. In animal studies, it proved no teratogenic effect over the growing fetus.

In cases of suspected PE, simple chest skiagram with abdominal shielding shows significant changes in 70\% of PE cases. The changes are in the form of focal oligemia, atelectasis, pleural effusion, and elevation of hemidiaphragm. There

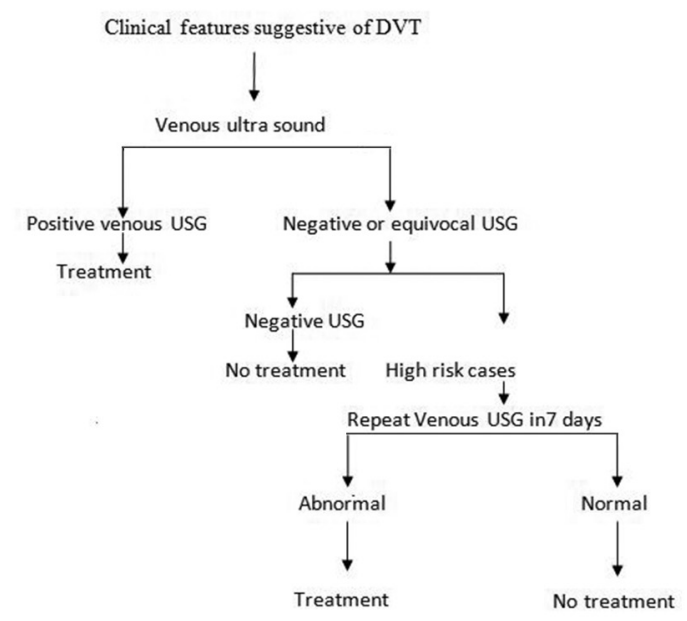

Fig. 1 Flowchart showing the diagnostic methodology for deep vein thrombosis (DVT). USG, ultrasonography. ${ }^{14}$ may be rare X-ray findings such as wedge-shaped infiltrates (Hampton's hump) or decreased vascularity (Westermark's sign ). ${ }^{19} \mathrm{D}$-dimer testing in pregnancy is not useful in the diagnosis of PE as physiologically the D-dimer levels may increase during pregnancy.

Electrocardiogram in case of PE shows tachycardia as the common finding. There will be right-axis deviation with S1Q3T3 pattern and nonspecific T-wave inversion in PE.

Two-dimensional (2D) echo is useful for visualization of a thrombus, right atrial enlargement, and right ventricle dilation with decreased contractility in case of PE.

\section{Ventilation/Perfusion Scan}

In case of PE, perfusion scanning can be done by injecting radio isotope-labeled albumin. Ventilation scan is inhalation of radiolabeled aerosols, and the distribution is evaluated by gamma camera. With the comparison of two images, the results are interpreted like high or low probability. Nearly more than $90 \%$ of high-risk patients who have high-probability ventilation/perfusion (V/Q) scan have PE, but only 5 to $6 \%$ of low-risk patients with low-probability scan will have PE.

\section{Spiral Computed Tomographic Pulmonary Angiography} Spiral CTPA test involves visualization of pulmonary vasculature through $\mathrm{CT}$ scanner by injecting intravenous contrast (-Fig. 2).

Indium-111 platelet imaging is a diagnostic aid for VTE, where labeled platelets are injected into patient circulation. In case of active thrombosis, the platelets are accumulated at the affected site; images are obtained using gamma camera scintigraphy. For diagnosing DVT, this test has sensitivity of 90 to $95 \%$ and specificity of 95 to $100 \%{ }^{20}$

In case of thromboembolism of pregnancy and the diagnostic aids to be applied, one should be aware of fetal radiation exposure. Radiation exposure statistics due to diagnostic procedures are in - Table 3. ${ }^{21}$ Regarding fetal exposure, the American College of Obstetrics and Gynecology

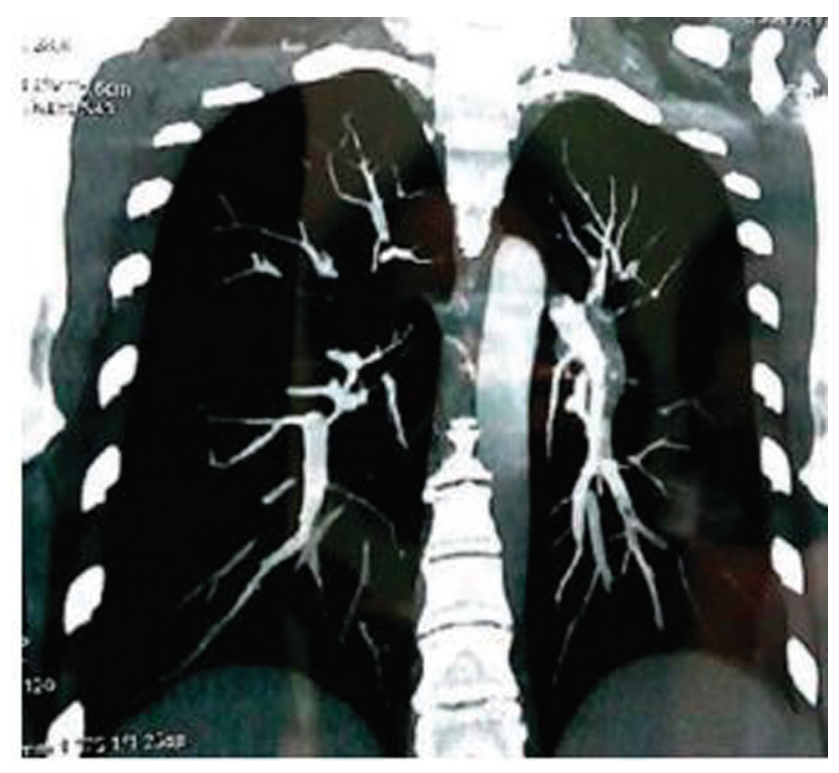

Fig. 2 Computed tomography pulmonary angiography showing right pulmonary artery thrombosis. 
(ACOG) advises that exposure to less than 5 rads has not been associated with fetal loss or fetalanomalies..$^{22} \mathrm{~A}$ combination of chest X-ray, $\mathrm{V} / \mathrm{Q}$ scan, and pulmonary angiography exposes the fetus to less than 0.5 rads. ${ }^{21,23}$ CTPA is with lower radiation level for the fetus than with $\mathrm{V} / \mathrm{Q}$ scan.

Maternal exposure-maternal breasts are greatly exposed to ionizing radiation because there is increased vascularity and glandularity of the breast, which makes it more radiosensitive and at increased cancer risk. CTPA is estimated to expose maternal breasts to 150 times more ionizing radiation than with $\mathrm{V} / \mathrm{Q}$ scanning accounting to 2 to 6 rads. ${ }^{24} \mathrm{MRI}$ and ultrasound have no teratogenic effects on the fetus. Fetal hypothyroidism can occur with maternal radiographic contrast exposure. Therefore, neonatal thyroid function should be tested during first week of neonatal life $^{25}$ in children of mothers exposed to radiation contrast media in pregnancy.

\section{Anticoagulant Medication and Their Use during Pregnancy}

- Unfractionated heparin (UFH)

- Low-molecular-weight heparin (LMWH)

- Oral anticoagulants-vitamin K antagonists (VKAs)

Table 3 Fetal radiation exposure due to diagnostic procedures

\begin{tabular}{|l|l|}
\hline $\begin{array}{l}\text { Type of test using ionizing } \\
\text { radiation }\end{array}$ & Fetal exposure in rads \\
\hline Chest X-ray & $<0.01$ \\
\hline Venography shielded & $<0.05$ \\
\hline Venography unshielded & 0.31 \\
\hline Pulmonary angiogram via & \\
\hline Brachial vein & 0.05 \\
\hline Femoral vein & $0.22-0.37$ \\
\hline Ventilation perfusion scan & $0.007-0.037$ \\
\hline Ventilation scan & $0.001-0.009$ \\
\hline Perfusion scan & $0.006-0.012$ \\
\hline $\begin{array}{l}\text { Spiral computed tomogra- } \\
\text { phy (CT) }\end{array}$ & 0.013 \\
\hline
\end{tabular}

\section{Unfractionated Heparin}

It is the mainstay of treatment for acute VTE and also for thromboprophylaxis during pregnancy. ${ }^{26}$ Extensive studies regarding the safety of UFH were done in nonpregnant women, but few studies were with pregnant cases. The prophylactic and therapeutic dosage is given in - Table 4. UFH is a heterogenous acidic mucopolysaccharide with a high molecular weight $(4,000-40,000 \mathrm{Da})$. It does not cross the placenta and has no fetal effects. ${ }^{27}$

\section{Mechanism of Action of Unfractionated Heparin}

It acts by activating AT, which in turn inactivates factors Xa and IX, XI, XII, and thrombin. ${ }^{28}$ The dosing of UFH is monitored by activated partial thromboplastin time (aPTT) with a prolongation of 1.5 to 2.5 times the baseline considered as therapeutic range. Direct measuring of serum heparin levels $(0.2-0.4 \mathrm{IU} / \mathrm{mL})$ also can be done. Barbour and colleagues stated that pregnant patients will require a higher dose of heparin than nonpregnant controls because of increase in fluid volume and renal clearance and degradation of heparin by placenta. ${ }^{29}$

The maternal complications with UFH include PPH, bleeding from surgical sites, heparin-induced thrombocytopenia (HIT), osteopenia, and heparin-induced skin allergies, but there are no fetal effects. The risk of hemorrhage that is $2 \%$ with UFH can be due to its dose and also concurrent use of other drugs that affect the platelet function such as ibuprofen, aspirin, and dextran. This can be reversed by using protamine sulfate. Dahlman reported nearly $5 \%$ of bone loss in UFH users. ${ }^{30}$

Heparin-induced thrombocytopenia is a very serious complication occurring in 1 to $30 \%$ patients. It is of two types. A benign and reversible form is seen after several days of therapy. A severe form occurs between 5 and 14 days after beginning of therapy. Clinically thrombocytopenia is associated with extension of VTE or formation of new arterial thrombi, more common with high-dose therapy ${ }^{30}$ First step to tackle the situation is to stop heparin, and other alternatives such as Coumadin, venacaval filters, and danaparoid sodium and hirudin can be used for managing VTE.

Heparin-induced skin necrosis is common in HIT but may occur in the absence of thrombocytopenia also. Apart from

Table 4 Prophylactic and therapeutic regimen of anticoagulants

\begin{tabular}{|l|l|l|}
\hline Drug name & Dosage & Monitoring \\
\hline Prophylactic LMWH & Enoxaparin $40 \mathrm{mg} \mathrm{SC}$ once a day & $\begin{array}{l}\text { Anti Xa levels of } 0.1-0.2 \mathrm{U} / \mathrm{mL} 4 \mathrm{~h} \text { after } \\
\text { injection }\end{array}$ \\
\hline Therapeutic LMWH & Enoxaparin $1 \mathrm{mg} / \mathrm{kg} / 12 \mathrm{~h}$ & $\begin{array}{l}\text { Anti Xa levels } 0.6-1.0 \mathrm{U} / \mathrm{mL} \text { tested after } \\
4 \mathrm{~h}\end{array}$ \\
\hline Prophylactic UFH & $\begin{array}{l}\text { 1st trimester: } 5,000-7,500 \mathrm{U} / 12 \mathrm{~h} \mathrm{SC} \\
\text { 2nd trimester: } 7,500-10,000 \mathrm{U} / 12 \mathrm{~h} \mathrm{SC} \\
\text { 3rd trimester: } 10,000 \mathrm{U} / 12 \mathrm{~h}\end{array}$ & $\begin{array}{l}\text { aPTT should be in normal range } \\
\text { Heparin levels of } 0.1-0.2 \mathrm{U} / \mathrm{mL}\end{array}$ \\
\hline Therapeutic UFH & $\geq 10,000 \mathrm{U}$ every $12 \mathrm{~h} \mathrm{SC}$ & $\begin{array}{l}\text { aPTT level should be } 1.5-2.5 \text { times more } \\
\text { than the control measured } 6 \text { h after } \\
\text { injection }\end{array}$ \\
\hline $\begin{array}{l}\text { Warfarin (postpartum period) only } \\
\text { therapeutic }\end{array}$ & $\begin{array}{l}\text { Start with } 5-10 \mathrm{mg} / \text { day orally; dose } \\
\text { can be adjusted according to INR tar- } \\
\text { get. (target INR 2-3) }\end{array}$ & $\begin{array}{l}\text { Overlap UFH or LMWH until INR is > 2 for } \\
>2 \text { days }\end{array}$ \\
\hline
\end{tabular}

Abbreviation: aPTT, activated partial thromboplastin time; INR, international normalized ratio; LMWH, low-molecular-weight heparin; SC, subcutaneous/subcutaneously; UFH, unfractionated heparin; VTE, venous thromboembolism. 
necrosis, pruritic rash and erythematous plaques are reported with long-term use in pregnant women compared with nonpregnant, short-term use. ${ }^{31}$

\section{Low-Molecular-Weight Heparin}

The drug is safe for use during pregnancy. ${ }^{32}$ LMWH are formed by depolymerization of UFH. It does not cross the placenta. Anticoagulant action of LMWH occurs by binding with AT III. The drug preferentially inactivates factor Xa, with minimal effect on thrombin. There is a decrease in incidence of hemorrhagic episodes with LMWH when compared with conventional UFH. The half-life of LMWH is two to four times that of $\mathrm{UFH},{ }^{33}$ thus leading to

- Greater bioavailability

- More predictable dose-response profile

- Longer half-life allowing once- or twice-a-day dosing

- Not necessary to monitor anticoagulant effect with aPTT or prothrombin time (PT)

- Decreased incidence of hemorrhagic complication ${ }^{34}$

- Decreased incidence of HIT ${ }^{35}$

- Ability to decrease the incidence of "heparin resistance"36

- Less risk of osteoporosis

The ACOG Committee concluded that preliminary evidence suggests that there is no greater risk of bone demineralizaton with LMWH. ${ }^{37}$ LMWH is to be administered subcutaneous dosage as follows:

- Dalteparin 200 U/kg once daily

- Tinzaparin $175 \mathrm{U} / \mathrm{kg}$ once daily

- Enoxaparin $12 \mathrm{mg} / \mathrm{kg}$ twice/once daily

\section{Anticoagulant Regimens}

Low-molecular-weight heparin is less affected by protamine sulfate..$^{38}$ It has to be decreased to a lower dose in case of renal impairment such as acute tubular necrosis as seen in abruption placentae.

The dose is then titrated to a target of anti-Xa levels of 0.6 to $1 \mathrm{IU} / \mathrm{mL}$ for twice-daily administration of LMWH or 1 to $2 \mathrm{IU} / \mathrm{mL}$ for once-daily administration. First anti-Xa level is generally measured 4 hours after the third or fourth dose. Though regular monitoring is not required for LMWH treatment, anti-Xa levels can be done whenever there is a suspicion of over- or underdosage.

\section{Intravenous Unfractionated Heparin}

Bolus of $80 \mathrm{U} / \mathrm{kg}$ of intravenous (IV) UFH is (in case of therapeutic administration) to be given, followed by continuous infusion of $18 \mathrm{U} / \mathrm{kg} / \mathrm{h} .{ }^{39}$

The target aPTT range will be laboratory specific. Once the target aPTT level is achieved, it should be checked once or twice daily. IV UFH can be transitioned to subcutaneous (SC) UFH or SC LMWH for long-term usage. It is also suggested by some authors that VKAs can replace UFH or LMWH from 13th week of gestation onward until term when the UFH or LMWH can be reintroduced. ${ }^{40}$

\section{Subcutaneous Unfractionated Heparin}

An initial dose of SC UFH is 17,500 units 12 hourly, and then the dose is titrated down to achieve a therapeutic aPTT range, which can be measured 6 hours after the second dose. Once a stable dose is achieved, aPTT can be tested once in 3 to 4 days of treatment, then weekly once. During the past 10 weeks of pregnancy, more frequent monitoring is warranted. ${ }^{41}$

\section{Fondaparinux}

It is a synthetic heparin that complexes with antithrombin-binding site for heparin to permit the selective inactivation of factor Xa but not thrombin. It has a comparable efficacy to both LMWH and UFH in pregnant women. The drug is excreted in urine. It has a half-life of 15 hours and can be taken in once-a-day dose, subcutaneously. It was demonstrated that there will be minimal umbilical cord plasma concentration confirming that very limited transplacental passage of the drug occurs. It does not lead to risk of HIT type 2. Use of fondaparinux should be advised to women with history of HIT type 2 or heparin allergies and those who have failed response to other anticoagulants.

\section{Vitamin K Antagonists}

Vitamin $\mathrm{K}$ antagonists block the vitamin K-dependent factors such as VII, IX, and X, as well as the anticlotting agents proteins $C$ and $S$. Though it is more effective for both primary and secondary preventions of VTE, stroke, myocardial infarction (MI), and systemic embolism due to atrial fibrillation and artificial cardiac valves, it is a pregnancy category $\mathrm{X}$ drug. The risk of warfarin embryopathy is greater if it is used in first trimester, which leads to nasal, midface hypoplasia, and malformations. Fetal hemorrhages are also reported. Therefore, it is advisable to use warfarin, preferably in the postpartum period as it is safe during lactation. ${ }^{42}$

The safety and efficacy of the newer oral anticoagulants such as dabigatran (direct thrombin inhibitor) and apixaban and rivaroxaban (both are factor X inhibitors) is not yet established in pregnancy and during breast-feeding. Though they are effective in prophylaxis and treatment of venous thrombotic disorders, further studies are necessary to define their role in obstetric practice.

\section{Treatment of Acute Deep Vein Thrombosis or Pulmonary Embolism}

Women with new onset of VTE during pregnancy should receive therapeutic anticoagulation and continued for 20 weeks. If this period expires before the end of postpartum period, prophylactic anticoagulation should be initiated and continued for 6 weeks to 6 months postpartum depending on the severity of TE and underlying risk factors. Before initiating, blood investigations such as grouping, hemoglobin, platelet count, baseline aPTT, and investigations for acquired or inheritable thrombophilia are to be undertaken. 


\section{Fixed Dose and Adjusted Dose Anticoagulants}

The term "fixed dose" is used in reference to an empiric dose of heparin (UFH or LMWH) used for thromboprophylaxis.

The term "adjusted dose" refers to a heparin dose that is altered based on laboratory tests used to monitor the anticoagulant effect. ${ }^{43}$ The adjusted dose heparin is used in acute VTE. In acute VTE, at least 30,000 units of IV UFH in 24 hours should be given to achieve a therapeutic level of heparin. The aPTT level should be at least 1.5 times the control. ${ }^{44}$ IV heparin therapy must be continued for 2 to 5 days, followed by a regimen of SC heparin for 3 months. Treatment with LMWH is an acceptable alternative to UFH, in the dose of $20 \mathrm{mg}$ of enoxaparin subcutaneously twice daily.

The Committee on Obstetric Practice ${ }^{45}$ concluded that patients with DVT, PE, or thrombophilic disorders may be treated with LMWH or traditional heparin, both of which give equally good results.

\section{Intrapartum Usage}

Regional anesthesia is contraindicated within 18 to 24 hours of LMWH administration. Thus LMWH should be converted to UFH at 36 weeks of gestation. During vaginal delivery or lower segment cesarean section (LSCS), there is no risk of hemorrhage when performed more than 24 hours after the last dose of LMWH. Heparin anticoagulation may be restarted 3 to 6 hours after vaginal delivery and 12 hours after LSCS. In patients at increased risk of operative bleeding such as placenta previa, placenta accreta, and low risk of propagation of clot, the effects of heparin can be reversed with protamine sulfate. One milligram of protamine sulfate neutralizes 100 units of heparin. Slightly less than the exact calculated dose is administered intravenously over a period of 30 minutes. As heparin is cleared rapidly from circulation, the excessive protamine sulfate may act as an irreversible anticoagulant when given in higher doses. The dose should not exceed $50 \mathrm{mg}$ at any time, and it can neutralize 5,000 units of circulating heparin.

In women on therapeutic LMWH later in pregnancy, termination of pregnancy at 39 weeks is to be planned. Otherwise when she gets into spontaneous labor with full anticoagulation, the risk of PPH will be high and LMWH cannot be totally reversed with protamine sulfate.

In high-risk women with therapeutic LMWH, UFH should be given at least 36 hours prior to delivery and the infusion should be stopped 4 to 6 hours prior to anticipated delivery. There should be normalized aPTT prior to administration of regional anesthesia. ${ }^{46}$

In low-risk women on therapeutic LMWH or women on twice-a-day regimen of prophylactic LMWH, the evening dose of LMWH should be avoided when cesarean section is planned next morning and if no other drug that interferes with coagulation is used.

Therapeutic anticoagulation is associated with increased risk of PPH so that active management of third-stage labor is mandatory. Recently the effect of adding 2 IU oxytocin over 5 minutes to a standard dose of low-dose infusion for
4 hours (10 units oxytocin in $500 \mathrm{~mL}$ of normal saline given IV at $36 \mathrm{~mL} / \mathrm{h}$ for 4 hours) was associated with less blood loss. The addition of $2 \mathrm{IU}$ of oxytocin did not exert any cardiovascular adverse effects. ${ }^{47}$

Antenatal mothers on continuous oral anticoagulants presenting in active stage of labor, without prior antenatal checkups, are at high risk of PPH. In such cases, parenteral vitamin $\mathrm{K}$ is highly useful. Vitamin K parenteral administration restores the clotting factors within 12 hours. However, if immediate delivery is anticipated, fresh frozen plasma has to be kept ready to tackle the PPH. Coumadin anticoagulation may be started on first postoperative or postpartum day, but the Royal College of Obstetricians and Gynaecologists (RCOG) recommends waiting till fifth day postpartum. There should be transition with heparin and Coumadin for 5 days as there can be a paradoxical increase in activated protein C (APC) resistance and factor VIII after Coumadin.

Those planning for labor analgesia by epidural medication are required to follow a protocol to avoid spinal extradural hematoma collection. Epidural puncture can be done 24 hours following a therapeutic dose of LMWH and 12 hours after the last dose of prophylactic LMWH. In case of UFH, the aPTT needs to be less than 40 before an epidural puncture. For VKA, the PT must be less than 1.5 for a safe epidural puncture, and the oral anticoagulant needs to be stopped 4 to 5 days before the procedure to achieve this prothrombin time standard. There is no contraindication for epidural puncture, and no time gap is necessary, when the patient is on aspirin or other nonsteroidal anti-inflammatory drugs. ${ }^{13}$

\section{Anticoagulants and Breast-Feeding}

Unfractionated heparin is not secreted into breast milk and so is quite safe during lactation period, but long term usage can lead to bone mineral loss, especially with higher dose than 15,000 U/day for longer than 6 months. The bone density recovers over time after discontinuing heparin. Mothers can be reassured regarding lack of significant bone mineral loss on using prophylactic LMWH. ${ }^{48}$ Warfarin is safe during lactation as it is not secreted into milk. Both heparin and oral warfarin can be initiated simultaneously after delivery as detailed previously, and heparin can be discontinued after 5 days. Postpartum mothers need a longer time to achieve target international normalization ratio (INR). Postpartum suppression of lactation with estrogens or oral contraceptive pills is not advisable as both of them can increase the risk of recurrent VTE.

\section{Thromboprophylaxis (Use in Patients at Risk of Venous Thromboembolism)}

Preconceptional counseling is necessary for women at risk for VTE and also in those with a previous history of VTE. Women on long term warfarin therapy should be advised to take heparin as the former is well known to be associated with "warfarin embryopathy." This complication is more common when the drug is taken between 6 and 12 weeks of pregnancy. 
As shown in the - Table $\mathbf{3}$, for patients at low risk, ${ }^{49}$ early mobilization is advised as in preterm $C$ section for uncomplicated pregnancy with no other risk. In those at moderate and severe risk, LMWH is needed, but one should know the risk of bleeding as a complication. Complications from anticoagulants both UFH and LMWH are as high as $2 \%{ }^{50}$ Women with history of previous VTE are at high risk of recurrent VTE in pregnancy. Risk is high during puerperal period. ${ }^{51}$ For women following in vitro fertilization complicated by ovarian hyperstimulation syndrome (OHSS), thromboprophylaxis with LMWH is recommended during the first trimester. ${ }^{52}$

During ante- and postpartum periods, graduated elastic compression stockings or pneumatic compression devices are recommended for all women with previous VTE. Pneumatic compression devices and stockings improve the blood flow, decrease stasis, and increase fibrinolysis. ${ }^{53}$ Thus they decrease the incidence of DVT by nearly 60\%. The left lateral position of antenatal mothers is another technique that can the reduce risk of VTE.

Postpartum thromboprophylaxis at 6 weeks (LMWH/warfarin) is recommended for all women with previous VTE. ${ }^{54}$ The indication for antepartum prophylaxis should be evaluated in each patient. Patients with previous episode of VTE and those with high-risk thrombophilic conditions such as AT III deficiency, antiphospholipid antibody syndrome (APLAS) syndrome, homozygosity for prothrombin G20210A variant, and factor V Leiden should be identified. The eligible patients must receive antenatal thromboprophylaxis as recommended by the RCOG and American College of Chest Physicians ${ }^{55}$ (-Table5). In women with previous history of VTE that was not related to pregnancy but was associated with a risk factor that is no longer present and who have no additional risk factors or thrombophilia, antenatal anticoagulation is not required. ${ }^{56}$ Women with

Table 5 Recommended thromboprophylaxis as per risk stratification

\begin{tabular}{|l|l|l|}
\hline Low risk & $\begin{array}{l}\text { Uncomplicated } \\
\text { preterm LSCS }\end{array}$ & $\begin{array}{l}\text { Management-early } \\
\text { mobilization }\end{array}$ \\
\hline Moderate risk & Age $>35$ y, BMI & LMWH, compressive \\
& $>30$ & leg stockings \\
$>3$ deliveries & \\
& Preeclampsia & \\
Immobility $>4$ & \\
days prior to LSCS & \\
& Emergency LSCS & \\
& Intrauterine & \\
infections & \\
& Varicose veins of & \\
& severe degree & \\
\hline High risk & Cesarean & Compressive \\
& hysterectomy & stocking apart from \\
& $>2$ moderate risk & LMWH \\
& factors & \\
& Past history of & \\
& DVT & \\
& History of & \\
& thrombophilia & \\
\hline
\end{tabular}

Abbreviation: BMI, body mass index; DVT, deep vein thrombosis; LSCS, lower segment cesarean section; LMWH, low-molecular-weight heparin.
AT deficiency are at a high risk of pregnancy-related VTE ${ }^{57}$ and definitely deserve antepartum prophylaxis of VTE.

Postthrombotic syndrome is a long-term complication of thrombosis, which affects $60 \%$ of patients with DVT and is a cause of significantmorbidity. ${ }^{58}$ Pain, skin discoloration, and even skin ulcers occur. The risk of this syndrome can be reduced by $50 \%$ with the simple use of elastic compression stockings up to 2 years. ${ }^{59}$

\section{Inferior Venacaval Filters}

They can be used during pregnancy also, ${ }^{60}$ but the absolute indications include the following:

- Where conventional anticoagulation is contraindicated such as during active bleeding following recent surgery or hemorrhagic stroke.

- Conventional anticoagulation is ineffective such as developing new VTE despite being anticoagulated.

- Significant bleeding occurs as a complication of anticoagulant therapy.

- Skin allergy and HIT where anticoagulants cannot be used.

The pulmonary vessels cannot tolerate repeated thromboembolic episodes as they are already affected by prior PE and chronic pulmonary hypertension. Temporary retrievable IVC filters are ideal for young patients who have temporary risk for VTE (i.e., pregnancy). ${ }^{61}$

\section{Thrombolysis/Thrombectomy}

Thrombolytic therapy with recombinant tissue plasminogen activator "alteplase" should be reserved for pregnant patients with life-threatening acute PE (with severe hypotension and shock), but the risk of maternal hemorrhage is very high with thrombolytic agents. When thrombolytic therapy is initiated, loading dose of UFH is withheld, but the same can be given in form of infusion at the rate of $18 \mathrm{U} / \mathrm{kg} / \mathrm{h}$. After stabilizing the patient, LMWH can be initiated and maintained. ${ }^{46}$

Ancrod, derived from Malayan pit viper venom, used as thrombolytic agent is contraindicated in pregnancy. The drug can increase the risk of fetal death and PPH.

A systematic review of case series of 172 pregnant women treated with thrombolytic agents reported $1 \%$ maternal morbidity, $6 \%$ fetal loss, $8 \%$ incidence of maternal hemorrhage, ${ }^{62}$ and $10 \%$ preterm births. Use of thrombolytics within 8 hours of delivery in spite of the risk of $\mathrm{PPH}$ is considered to be a lifesaving measure when other measures have failed. ${ }^{63}$

\section{Pulmonary Embolism in Late Pregnancy and Labor}

When antenatal patients develop sudden onset of dyspnea and tachypnea, one should suspect PE. Respiratory symptoms are present in $90 \%$ of PE cases. Other presenting symptoms include hemoptysis, wheezing chest pain, and syncope.

Patients presenting with PE in late pregnancy should be treated with supplemental oxygen and IV heparin. Once the patient is stabilized hemodynamically, a temporary venacaval 
filter should be placed to prevent recurrent thromboembolic episodes. ${ }^{64}$ All anticoagulants should be stopped when there is initiation of labor pains, and if the aPTT is prolonged at the time of active stage of labor, protamine sulfate can be given to prevent severe PPH. Compatible blood should be kept ready. LSCS should not be done while the patient is fully anticoagulated. This will predictably lead to uncontrollable bleeding leading to maternal death. Surgical delivery should not be undertaken unless there is an absolute indication for operative delivery.

Management of pregnancy at term with massive PE requires coordination of the obstetrician, anesthesiologist, interventional radiologist, and CT surgeon. Any surgical intervention should be for maternal indications only. ${ }^{65}$ Mortality with PE is high, as antenatal patients will have poor tolerance to positive-pressure ventilation and compromised cardiac output that occurs during vaginal deliveries and operative deliveries. Perimortem cesarean can be considered in an attempt to save the fetus. Once emptying of the uterus is completed, there is a better performance of the cardiopulmonary resuscitation (CPR) for the patient. The surgical or radiologic interventions such as pulmonary angiography with percutaneous mechanical clot fragmentation and placement of an IVC filter should be considered in massive PE cases, which, at times, save the life. When this approach fails, immediate cardiopulmonary bypass with surgical embolectomy followed by LSCS and placement of IVC filters should be considered.

\section{Ovarian Vein Thrombosis}

Thrombosis of ovarian veins occurs during postpartum period. In $50 \%$ of cases of ovarian vein thrombosis (OVT), there is positive history of inherited hemophilias.

Symptoms of OVT include right or left iliac pain and tenderness, fever, chills, pain, and vomiting. Most OVTs occur due to uterine infection. Right side is more affected than left due to the retrograde blood flow. OVT is often confused with appendicitis or ovarian torsion. Complications in untreated OVT include septic thrombophlebitis, thrombosis of IVC or renal vein, PE, and death. OVT is confirmed by CT scan apart from Doppler, USG, and MRI. Treatment includes broad-spectrum antibiotics and anticoagulants for at least 1 week after resolution of fever. If extensive thrombus into renal vein or IVC is noted, anticoagulation for a minimum of 3 months is advised. ${ }^{66}$

\section{Septic Pelvic Thrombophlebitis}

Septic pelvic thrombophlebitis is a condition characterized by pelvic vein inflammation and infected thrombosis following cesarean section or septic abortion. It occurs in 1:3,000 deliveries and 4- to 10 -folds higher after LSCS. ${ }^{67}$ Women with preeclampsia are with increased risk. There may be OVT or thromboses in the small vessels nearby the main ovarian vein. It usually manifests in the form of prolonged puerperal fever with or without chills and rigors. Broad-spectrum antibiotics that include aminoglycosides and cephalosporins are the mainstay of treatment.
"Superficial phlebitis" is a term used to describe inflamed superficial veins that lead to clinical features such as pain, tenderness, induration, and erythema of one of the superficial veins. The inflammation leads to thrombosis. The main risk period is antenatal and immediate postpartum. Patients with history of inherited hemophilias, obesity, and prolonged immobilization are at greater risk. ${ }^{68}$

Differential diagnosis includes DVT, cellulitis, lymphangitis, insect bite, and erythema nodosum. Superficial phlebitis and DVT can coexist. Therefore, compression ultrasound (CUS) examination is mandatory in all cases of superficial venous thrombosis. In a systematic review of 2,500 cases of superficial vein thrombosis, LMWH is the ideal drug for prevention of thromboembolism, recurrence of superficial venous thrombosis, or its extension to the nearby veins.

\section{Personal Experiences of Venous Thrombosis in Association with Pregnancy Cortical Sinus Venous Thrombosis due to APLA} Syndrome Complicating Pregnancy with Seven Times Recurrent Pregnancy Loss: Case Report

A 25-year-old woman was admitted in view of bad obstetric history, with married life of 7 years with 4 months amenorrhea. She was gravida 8 with previous seven first-trimester abortions. Last abortion was 1.5 years ago, before presentation to us. There was no history of consanguinity, nor were there any known genetic disorders in the family.

In view of the fact that there was no live child in spite of seven pregnancies, she was thoroughly investigated. The renal function and hepatic function were normal. Hemoglobin was $10.4 \mathrm{~g} / \mathrm{dL}$. Venereal disease research laboratory (VDRL), viral markers including human immunodeficiency virus (HIV) and hepatitis B virus surface antigen ( $\mathrm{HBs} A g$ ) were nonreactive. Blood group was B positive. Her erythrocyte sedimentation was very high at $190 \mathrm{~mm}$ in first hour. The coagulation parameters were normal. Oral glucose tolerance test was normal. There was mild leucocytosis of $13,000 / \mathrm{mm}^{3}$. An obstetric ultrasound examination showed a live fetus of 16 weeks' gestation. The antiphospholipid antibodies were positive at immunoglobulin $\mathrm{G}(\mathrm{IgG})-14 \mathrm{GPL}$ units (< 10 negative), immunoglobulin M (IgM)-22 MPL units ( $>12$ positive), and immunoglobulin A ( $\operatorname{IgA})-7$ APL units ( $<15$ negative).

The woman was advised LMWH therapy, but she did not consent and was lost to follow-up. One month later, she presented with headache and left hemiparesis of 3-day duration. The MRI of the brain was suggestive of venous infarct with pressure effects ( $\boldsymbol{- \text { Fig. }} \mathbf{3}$ ). There was further deterioration of sensorium, she was operated, and left temporoparietal decompressive craniectomy was performed. As she recovered, she was put on LMWH till term. Elective cesarean was done 1 month before due date, and a healthy male child was delivered.

\section{Bilateral Retinal Artery Thrombosis in Preeclampsia: \\ Case Report}

A 23-year-old female patient, primigravida was referred from a community hospital in view of severe preeclampsia for safe confinement. At the time of admission, her BP was 
210/130 mm Hg. Urine proteins 3+. Her bone mass index (BMI) was $33 \mathrm{~kg} / \mathrm{m}^{2}$. She complained of diminished vision that progressed to complete blindness. The patient was immediately put on Pritchard's regimen of magnesium sulfate and IV labetalol. The ophthalmologist found bilateral retinal artery thrombosis and papilledema of both the eyes on funduscopic examination ( - Fig. 4). Because it was term pregnancy, induction of labor was done on the same day and she delivered a live male child of $2.2 \mathrm{~kg}$. After 6 hours post delivery, the patient was kept on heparin subcutaneously for 1 week. She was evaluated and diagnosed with bilateral retinal artery thrombosis due to preeclampsia and was on Acitrom (acenocoumarol) for 2 months. She was regularly followed on monthly basis, but she had only partial regain of vision.

\section{Splenic Vein Thrombosis: Case Report}

A 28-year-old gravida 4 with one live child and two miscarriages (at first trimester) came to the hospital with severe abdominal pain of 2-day duration. On examination the patient was found to be a case of severe form of preeclampsia. Her uterus was of 34 weeks of gestation with presence of fetal heart sounds. Left hypochondrial tender mass was palpable suggestive of splenomegaly (-Fig. 5). Ultrasound examination revealed a single live fetus of 34 weeks besides splenomegaly, and there were no signs of placental abruption (-Fig. 6). Splenic vein Doppler showed thrombosis of the vein. As the patient went into severe hypotension and severe pain, an emergency LSCS was done. The baby was alive and was transferred to neonatal intensive care unit (ICU). In the same setting, splenectomy was also done as the spleen was congested and gangrenous (-Fig. 7). The patient recovered well after the procedure. Postoperatively, she was advised to take LMWH for 1 week, later followed by VKAs for 2 months.

\section{Bilateral Subclavian Venous Thrombosis in Postpartum Period}

A patient underwent a repeat cesarean operation, in Gandhi Hospital/Medical College. At the time of admission, preoperatively her serologic investigations along with coagulation

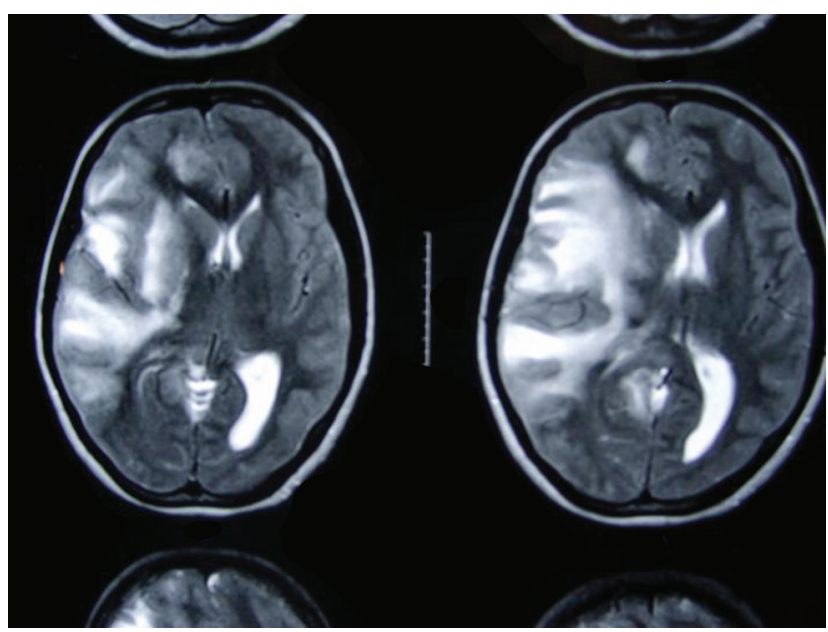

Fig. 3 T2-weighted cranial magnetic resonance imaging showing venous infarct in right cerebral hemisphere, mass effect, and midline shift. profile were normal. Intraoperatively she had severe $\mathrm{PPH}$, controlled with whole blood transfusion. Because her platelet count decreased to $30,000 / \mathrm{mm}^{3}, 4$ units of random donor platelets were also transfused. The patient completely recovered from hemorrhagic shock. On the second postoperative day, massive edema of both the upper limbs and anterior chest wall was noticed. On further evaluation, the D-dimer value was $365 \mathrm{ng} / \mathrm{mL}$ (normal value < $500 \mathrm{ng} / \mathrm{mL}$ ) and plasma fibrinogen $280 \mathrm{mg} / \mathrm{dL}$ (normal value is $150-400 \mathrm{mg} / \mathrm{dL}$ ). Doppler of neck vessels revealed high Doppler velocity flow due to distal obstruction, partial focal thrombosis with peripheral flow seen in both subclavian veins in their proximal part. Distal portion of both subclavian veins were normal. Two-dimensional echocardiography was normal including of the right atrium. A diagnosis of bilateral subclavian venous thrombosis was made, and $60 \mathrm{mg}$ of LMWH was started twice daily. For limb edema, elevation of limb and pressure bandages were applied. After 11 th postoperative day, repeat Doppler study revealed an improvement of flow on right side, where as there was complete recanalization of the left

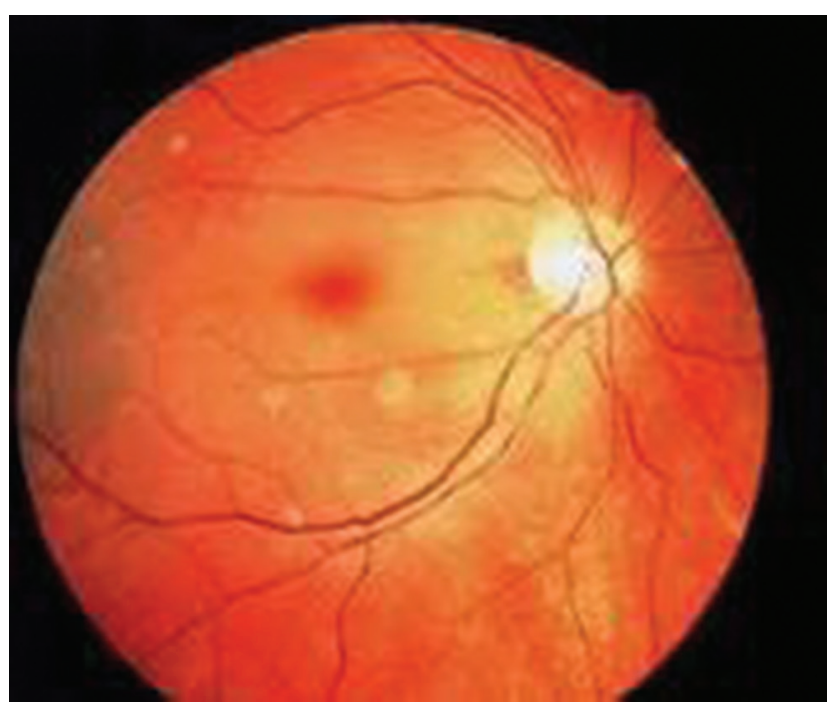

Fig. 4 Central retinal artery thrombosis resulting in cherry red spot.

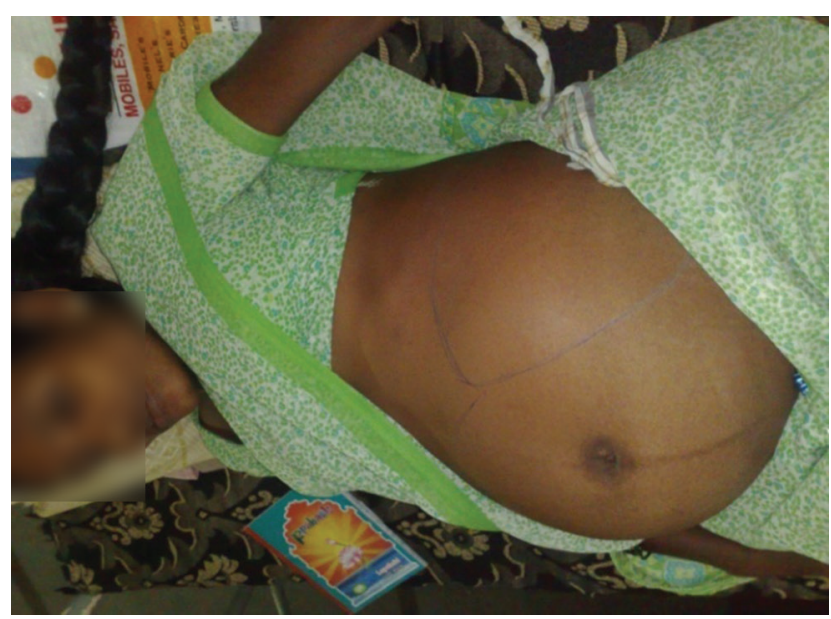

Fig. 5 Gravid uterus with tender, enlarged spleen due to splenic vein thrombosis. 


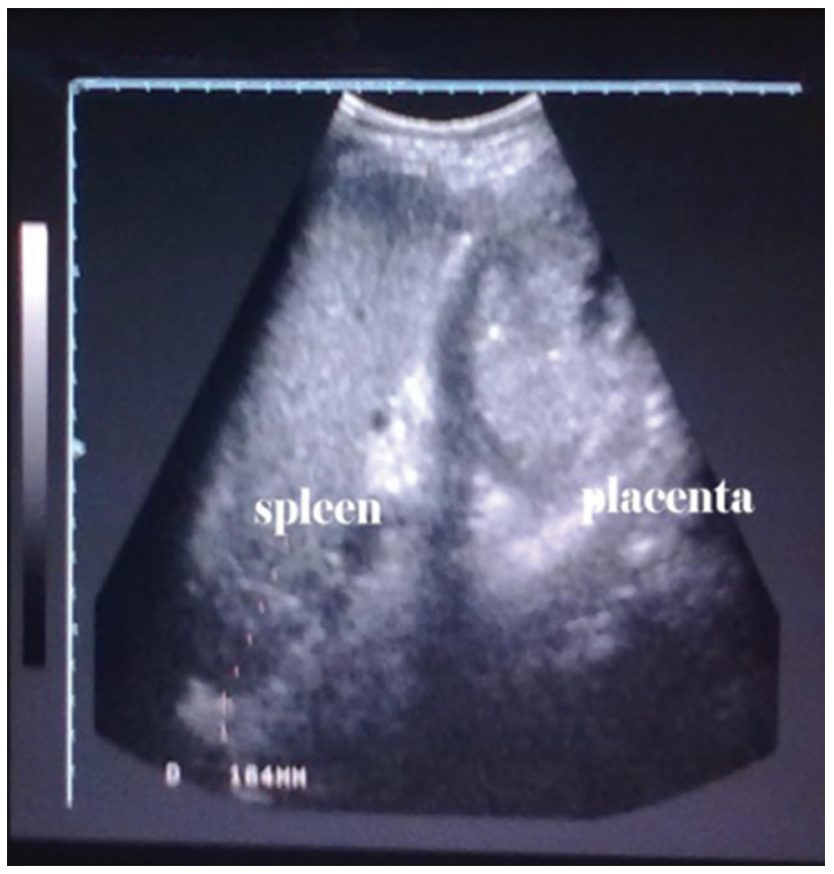

Fig. 6 Antenatal scan showing enlarged spleen and gravid uterus.

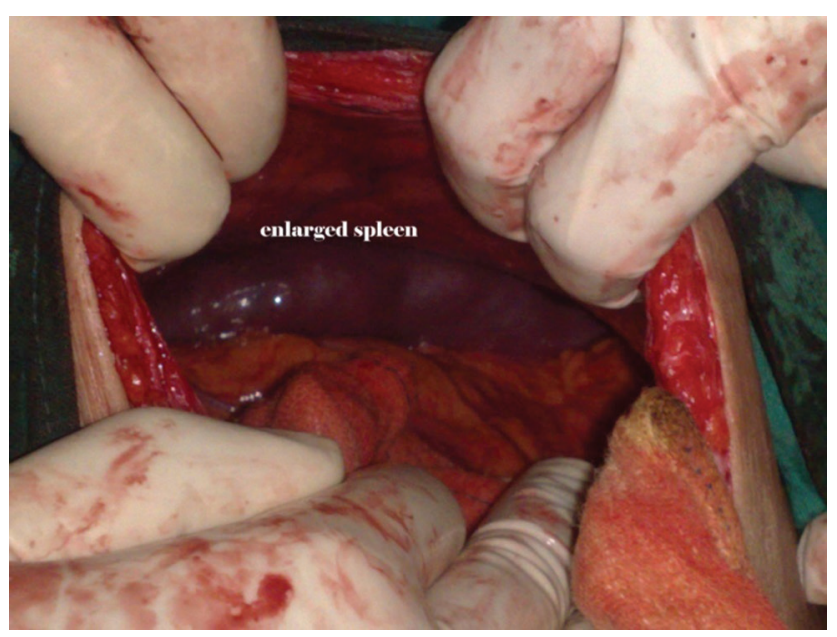

Fig. 7 Intraoperative finding of enlarged, congested, and gangrenous spleen.

subclavian vein. The patient was put on $2 \mathrm{mg}$ of Acitrom (acenocoumarol) per day with appropriate dietary instructions and monitoring of INR. She was advised to take oral anticoagulants for 3 months and fortnightly follow-up.

In this case the exact mechanism of venous thrombosis was unknown except that the patient was obese, with BMI of $32 \mathrm{~kg} / \mathrm{m}^{2}$. Platelet transfusion could be one important factor leading to thrombotic episode.

\section{Conclusion}

World over, VTE is a common cause of morbidity and the most common cause of maternal death is due to PE. The most critical period of VTE in postpartum period is the first 4 weeks after delivery. Pain in the calf muscles especially left side and increase in the calf circumference of more than $2 \mathrm{~cm}$ and presenting in the first trimester of leg symptoms are highly predictive of DVT in pregnancy.

CUS is the mainstay of diagnostic aid for DVT and PE. A very prolonged treatment of anticoagulants and compression stockings are needed in patients with past history of VTE which includes ante- and postpartum period. The most convenient drug regimen is once-daily weight-adjusted LMWH. The risk of postthrombotic syndrome can be reduced to $50 \%$ by wearing the elastic compression stockings on the affected leg for up to 2 years after the acute episode.

\section{Funding}

None.

\section{Conflicts of Interest}

None.

\section{References}

1 Christian MP, Charles JL. Thromboembolic disorders in pregnancy. In: Obstetrics-Normal and Problem Pregnancies. 7 ed. New Delhi, India: Elsevier with arrangement with Relex India Pvt Ltd.; 2017:965-977

2 Meng K, Hu X, Peng X, Zhang Z. Incidence of venous thromboembolism during pregnancy and the puerperium: a systematic review and meta-analysis. J Matern Fetal Neonatal Med 2015;28(3):245-253

3 Creanga A, Berg CJ, Syverson C, Seed K, Bruce FC, Callaghan WM. Pregnancy-related mortality in the United States, 2006-2010. Obstet Gynecol 2015;125(1):5-12

4 Sultan AA, West J, Tata LJ, Fleming KM, Nelson-Piercy C, Grainge MJ. Risk of first venous thromboembolism in and around pregnancy: a population-based cohort study. Br J Haematol 2012;156(3):366-373

5 Kamel H, Navi BB, Sriram N, Hovsepian DA, Devereux RB, Elkind MS. Risk of a thrombotic event after the 6-week postpartum period. N Engl J Med 2014;370(14):1307-1315

6 Ginsberg JS, Brill-Edwards P, Burrows RF, et al. Venous thrombosis during pregnancy: leg and trimester of presentation. Thromb Haemost 1992;67(5):519-520

7 Todd ME, Thompson JH Jr, Bowie EJ, Owen CA Jr. Changes in blood coagulation during pregnancy. Mayo Clin Proc 1965;40:370-383

8 Paul EM. Venous disease and thromboembolism. In: Obstetric Medicine. 6th ed. New Delhi, India: Jaypee Brothers Medical Publishers (P) Ltd.; 2015;221-233

9 Greer IA. Thrombosis in pregnancy: maternal and fetal issues. Lancet 1999;353(9160):1258-1265

10 Wu O, Robertson L, Twaddle S, et al; Thrombosis: Risk and Economic Assessment of Thrombophilia Screening (TREATS) Study. Screening for thrombophilia in high-risk situations: a meta-analysis and cost-effectiveness analysis. $\mathrm{Br} \mathrm{J}$ Haematol 2005;131(1):80-90

11 Nelson SM, Greer IA. Thrombophilia and the risk for venous thromboembolism during pregnancy, delivery, and puerperium. Obstet Gynecol Clin North Am 2006;33(3):413-427

12 Righini M, Jobic C, Boehlen F, et al; EDVIGE study group. Predicting deep venous thrombosis in pregnancy: external validation of the LEFT clinical prediction rule. Haematologica 2013;98(4):545-548

13 Terese TH, Denise JW, Rowlingson JC, et al. Regional anesthesia in the patient receiving antithrombotic or thrombolytic therapy: American Society of Regional Anesthesia and Pain Medicine Evidence-Based Guidelines (Third Edition). Reg Anesth Pain Med 2010;35(1):64-101 
14 Kassaï B, Boissel JP, Cucherat M, Sonie S, Shah NR, Leizorovicz A. A systematic review of the accuracy of ultrasound in the diagnosis of deep venous thrombosis in asymptomatic patients. Thromb Haemost 2004;91(4):655-666

15 Hirsh J, Hoak J; American Heart Association. Management of deep vein thrombosis and pulmonary embolism. A statement for healthcare professionals. Council on Thrombosis (in consultation with the Council on Cardiovascular Radiology), American Heart Association. Circulation 1996;93(12):2212-2245

16 Goodacre S, Sampson F, Thomas S, van Beek E, Sutton A. Systematic review and meta-analysis of the diagnostic accuracy of ultrasonography for deep vein thrombosis. BMC Med Imaging 2005;5:6

17 Spritzer CE, Evans AC, Kay HH. Magnetic resonance imaging of deep venous thrombosis in pregnant women with lower extremity edema. Obstet Gynecol 1995;85(4):603-607

18 Meaney JF, Weg JG, Chenevert TL, Stafford-Johnson D, Hamilton $\mathrm{BH}$, Prince MR. Diagnosis of pulmonary embolism with magnetic resonance angiography. N Engl J Med 1997;336(20):1422-1427

19 Tapson VF, Carroll BA, Davidson BL, et al; American Thoracic Society. The diagnostic approach to acute venous thromboembolism. Clinical practice guideline. Am J Respir Crit Care Med 1999;160(3):1043-1066

20 Ezekowitz MD, Pope CF, Smith EO. Indium 111 platelet imaging. In: Goldhaber SE, ed. Pulmonary Embolism and Deep Vein Thrombosis. Philadelphia, PA: WB Saunders; 1985:261-267

21 Toglia MR, Weg JG. Venous thromboembolism during pregnancy. N Engl J Med 1996;335(2):108-114

22 ACOG Committee on Obstetric Practice. ACOG Committee Opinion. Number 299, September 2004 (replaces No. 158, September 1995). Guidelines for diagnostic imaging during pregnancy. Obstet Gynecol 2004;104(3):647-651

23 Ginsberg JS, Hirsh J, Rainbow AJ, Coates G. Risks to the fetus of radiologic procedures used in the diagnosis of maternal venous thromboembolic disease. Thromb Haemost 1989;61(2):189-196

24 Hurwitz LM, Yoshizumi TT, Reiman RE, et al. Radiation dose to the female breast from 16-MDCT body protocols. AJR Am J Roentgenol 2006;186(6):1718-1722

25 Webb JA, Thomsen HS, Morcos SK; Members of Contrast Media Safety Committee of European Society of Urogenital Radiology (ESUR). The use of iodinated and gadolinium contrast media during pregnancy and lactation. Eur Radiol 2005;15(6):1234-1240

26 Ginsenberg JS, Hirsh J, Turner DC, Levine MN, Burrows R. Risk to the foetus of anticoagulant therapy during pregnancy. ThrombHemost 1989;16:197-203

27 Ginsberg JS, Kowalchuk G, Hirsh J, Brill-Edwards P, Burrows R. Heparin therapy during pregnancy. Risks to the fetus and mother. Arch Intern Med 1989;149(10):2233-2236

28 Bergqvist A, Bergqvist D, Hallböök T. Deep vein thrombosis during pregnancy. A prospective study. Acta Obstet Gynecol Scand 1983;62(5):443-448

29 Barbour LA, Smith JM, Marlar RA. Heparin levels to guide thromboembolism prophylaxis during pregnancy. Am J Obstet Gynecol 1995;173(6):1869-1873

30 Dahlman TC. Osteoporotic fractures and the recurrence of thromboembolism during pregnancy and the puerperium in 184 women undergoing thromboprophylaxis with heparin. Am J Obstet Gynecol 1993;168(4):1265-1270

31 Drew PJ, Smith MJ, Milling MA. Heparin-induced skin necrosis and low molecular weight heparins. Ann R Coll Surg Engl 1999;81(4):266-269

32 Crowther MA, Spitzer K, Julian J, et al. Pharmacokinetic profile of a low-molecular weight heparin (reviparin) in pregnant patients. A prospective cohort study. Thromb Res 2000;98(2):133-138

33 Hirsh J, Warkentin TE, Raschke R, Granger C, Ohman EM, Dalen JE. Heparin and low-molecular-weight heparin: mechanisms of action, pharmacokinetics, dosing considerations, monitoring, efficacy, and safety. Chest 1998;114 (5 Suppl):489S-510S

34 Carter CJ, Kelton JG, Hirsh J, Cerskus A, Santos AV, Gent M. The relationship between the hemorrhagic and antithrombotic properties of low molecular weight heparin in rabbits. Blood 1982;59(6):1239-1245

35 Junqueira DR, Perini E, Penholati RR, Carvalho MG. Unfractionated heparin versus low molecular weight heparin for avoiding heparin-induced thrombocytopenia in postoperative patients. Cochrane Database Syst Rev 2012;12(9):CD007557

36 Warkentin TE, Levine MN, Hirsh J, et al. Heparin-induced thrombocytopenia in patients treated with low-molecular-weight heparin or unfractionated heparin. N Engl J Med 1995;332(20):1330-1335

37 American College of Obstetricians and Gynecologists Committee Opinion: Anticoagulation with low-molecular-weight heparin during pregnancy. Number 211, November 1998. Int J Gynaecol Obstet 1999;65(1):89-90

38 Lakshmi S, Gita A. Thromboembolic disorders. In: Essentials of Obstetrics. New Delhi, India: Wolters Kluver (India) Pvt Ltd.; 2015:815-826

39 Hirsh J, Bauer KA, Donati MB, Gould MM, Samama M, Weitz JI. Parenteral anticoagulants: American College of Chest Physicians Evidence based clinical practice guidelines (8 th Edition). Chest 2008;133(6 Suppl):141S-159S

40 Bates SM, Greer IA, Middeldorp S, Veenstra DL, Prabulos AM, Vandvik PO. VTE, thrombophilia, antithrombotic therapy, and pregnancy: Antithrombotic Therapy and Prevention of Thrombosis, 9th ed: American College of Chest Physicians Evidence-Based Clinical Practice Guidelines. Chest 2012;141 (2 Suppl):e691S-e736S

41 Schapkaitz E, Jacobson BF, Manga P, et al; South African Society of Thrombosis and Haemostasis. Recommendations for the anticoagulation of pregnant patients with mechanical heart valves. S Afr Med J 2015;105(9):733-738

42 Hirsh J, Dalen J, Anderson DR, et al. Oral anticoagulants: mechanism of action, clinical effectiveness, and optimal therapeutic range. Chest 2001;119(1 Suppl):8S-21S

43 van Dongen CJ, van den Belt AG, Prins MH, Lensing AW. Fixed dose subcutaneous low molecular weight heparins versus adjusted dose unfractionated heparin for venous thromboembolism. Cochrane Database Syst Rev 2004;(4):CD001100

44 Raschke RA, Reilly BM, Guidry JR, Fontana JR, Srinivas S. The weight-based heparin dosing nomogram compared with a "standard care" nomogram. A randomized controlled trial. Ann Intern Med 1993;119(9):874-881

45 Siragusa S, Cosmi B, Piovella F, Hirsh J, Ginsberg JS. Lowmolecular-weight heparins and unfractionated heparin in the treatment of patients with acute venous thromboembolis: results of a meta-analysis. Am J Med 1996;100(3):269-277

46 Regitz-Zagrosek V, Roos-Hesselink JW, Bauersachs J, et al; ESC Scientific Document Group. 2018 ESC guidelines for the management of cardiovascular diseases during pregnancy. Eur Heart J 2018;39(34):3165-3241

47 Cauldwell M, Steer PJ, Swan L, Uebing A, Gatzoulis MA, Johnson MR. The management of the third stage of labour in women with heart disease. Heart 2017;103(12):945-951

48 Le Templier G, Rodger MA. Heparin-induced osteoporosis and pregnancy. Curr Opin Pulm Med 2008;14(5):403-407

49 James AH, Jamison MG, Brancazio LR, Myers ER. Venous thromboembolism during pregnancy and the postpartum period: incidence, risk factors, and mortality. Am J Obstet Gynecol 2006;194(5):1311-1315

50 Greer IA, Nelson-Piercy C. Low-molecular-weight heparins for thromboprophylaxis and treatment of venous thromboembolism in pregnancy: a systematic review of safety and efficacy. Blood 2005;106(2):401-407 
51 De Stefano V, Martinelli I, Rossi E, et al. The risk of recur-rent venous thromboembolism in pregnancy and puerperium without antithrombotic prophylaxis. $\mathrm{Br} \mathrm{J}$ Haematol 2006; 135(3):386-391

52 Sennström M, Rova K, Hellgren M, et al. Thromboembolism and in vitro fertilization-a systematic review. Acta Obstet Gynecol Scand 2017;96(9):1045-1052

53 Robert DA, Charles JL. The diagnosis and treatment of thromboembolic disease in pregnancy. In: Obstetric Intensive Care Manual. New Delhi, India: Tata McGraw-Hill Publishing Company Ltd.; 2005:79-95

54 Bates SM, Greer IA, Pabinger I, Sofaer S, Hirsh J. Venous thromboembolism, thrombophilia, antithrombotic therapy, and pregnancy: American College of Chest Physicians Evidence-Based Clinical Practice Guidelines (8th Edition). Chest 2008;133(6, Suppl):844S-886S

55 Report of the RCOG working party on prophylaxis against thromboembolism in gynaecology and obstetrics. Green Top guidelines 37a. London, UK: Royal College of Obstetrics and Gynaecology; 2015

56 Pabinger I, Grafenhofer H, Kaider A, et al. Risk of pregnancy-associated recurrent venous thromboembolism in women with a history of venous thrombosis. J Thromb Haemost 2005;3(5):949-954

57 McColl MD, Ramsay JE, Tait RC, et al. Risk factors for pregnancy associated venous thromboembolism. Thromb Haemost 1997;78(4):1183-1188

58 McColl MD, Ellison J, Greer IA, Tait RC, Walker ID. Prevalence of the post-thrombotic syndrome in young women with previous venous thromboembolism. Br J Haematol 2000;108(2):272-274
59 Thomas LA, Summers RR, Cardwell MS. Use of Greenfield filters in pregnant women at risk for pulmonary embolism. South Med J 1997;90(2):215-217

60 Milford W, Chadha Y, Lust K. Use of a retrievable inferior vena cava filter in term pregnancy: case report and review of literature. Aust N Z J Obstet Gynaecol 2009;49(3):331-333

61 Köcher M, Krcova V, Cerna M, Prochazka M. Retrievable Günther Tulip vena cava filter in the prevention of pulmonary embolism in patients with acute deep venous thrombosis in perinatal period. Eur J Radiol 2009;70(1):165-169

62 Turrentine MA, Braems G, Ramirez MM. Use of thrombolytics for the treatment of thromboembolic disease during pregnancy. Obstet Gynecol Surv 1995;50(7):534-541

63 Funakoshi Y, Kato M, Kuratani T, Shigemura M, Kaneko M. Successful treatment of massive pulmonary embolism in patients with acute deep venous thrombosis in perinatal period. Eur J Radiol 2009;70:165

64 Baglin TP, Brush J, Streff M; British Committee for Standards in Haematology Writing Group. Guidelines on use of vena cava filters. Br J Haematol 2006;134(6):590-595

65 Woodward DK, Birks RJ, Granger KA. Massive pulmonary embolism in late pregnancy. Can J Anaesth 1998;45(9):888-892

66 Klima DA, Snyder TE. Postpartum ovarian vein thrombosis. Obstet Gynecol 2008;111(2 Pt 1):431-435

67 Brown CE, Stettler RW, Twickler D, Cunningham FG. Puerperal septic pelvic thrombophlebitis: incidence and response to heparin therapy. Am J Obstet Gynecol 1999;181(1):143-148

68 Martinelli I, Cattaneo M, Taioli E, De Stefano V, Chiusolo P, Mannucci PM. Genetic risk factors for superficial vein thrombosis. Thromb Haemost 1999;82(4):1215-1217 